\title{
Enquadramentos, cenas dissensuais e 0 aparecer antierárquico: ação política e resistência em Judith Butler e Jacques Rancière ${ }^{1}$
}

\section{Frameworks, scenes of dissensus and the anti- hierarchical appearance: political action and resistance in Judith Butler and Jacques Rancière}

\author{
Ângela Cristina Salgueiro Marques ${ }^{2}$ \\ Lucas Henrique Nigri Veloso ${ }^{3}$ \\ Marco Aurélio Máximo Prado ${ }^{4}$
}

Resumo: $O$ artigo apresenta uma possivel articulação entre as abordagens de Jacques Rancière e Judith Butler acerca dos modos de aparecimento político de sujeitos vulneráveis em espaços enunciativos de dissenso e demanda por reconhecimento. Argumentamos que, ainda que por caminhos reflexivos distintos, ambos valorizam as resistências que desestabilizam e questionam as ordens hierárquicas as quais definem regimes normativos reguladores das visibilidades e legibilidades que autorizam e validam as experiências dos sujeitos e suas formas de vida. Aparecer é, ao mesmo tempo, a reconfiguração do sensível e a construção de novos quadros de sentido que permitem novas coordenadas de expressão e reconhecimento das vidas precárias. Isso envolve não só a consideração das vulnerabilidades dos corpos em ação, mas também as fabulações e imaginários que redesenham trajetórias sociohistóricas de sobrevivências e lutas por justiça.

Palavras-Chave: Cena de dissenso, aparecimento, enquadramentos, sobrevivencias

1 Este trabalho contou com o apoio da CAPES, do CNPq e da FAPEMIG.

2 Universidade Federal de Minas Gerais (UFMG). Belo Horizonte, MG, Brasil. http://orcid.org/0000-0002-2253-0374 E-mail: angelasalgueiro@gmail.com

3 Universidade Federal de Minas Gerais (UFMG). Belo Horizonte, MG, Brasil. http://orcid.org/ 0000-0002-9688-7819 E-mail: lucasnveloso@gmail.com

4 Universidade Federal de Minas Gerais (UFMG). Belo Horizonte, MG, Brasil. http://orcid.org/ 0000-0002-3207-7542 E-mail: mamprado@gmail.com 
Abstract: The article presents an attempt to articulate the approaches of Jacques Rancière and Judith Butler concerning the modes of political appearance of vulnerable subjects in enunciative spaces of dissent and demand for recognition. We argue that, although in different reflective ways, both value the resistances that destabilize and question the hierarchical orders that define normative regimes that regulate the visibilities and legibilities that authorize and validate the experiences of the subjects and their ways of life. Appearing is, at the same time, the reconfiguration of the sensible and the construction of new frames of meaning that allow new coordinates of expression and recognition of precarious lives. This involves not only considering the vulnerabilities of bodies in action, but also the fables and imagery that redraw socio-historical trajectories of survivals and struggles for justice.

Keywords: Scene of dissent, appearance, frameworks, survivals 


\section{Introdução}

Este artigo pretende construir uma reflexão acerca de aspectos e mudanças dos modos de aparição dos sujeitos na cena pública, interferindo nas coordenadas daquilo que pode ser representável e das formas de sua enunciação. Uma interferência na operação social e política que define aquilo e aqueles que serão legíveis e inteligíveis, instaura resistências que alteram quadros de sentido, ritmos e escalas de significação, proporcionando outras formas de apreender o visível e sua organização sensível. Jacques Rancière e Judith Butler, ainda que por caminhos distintos, têm desenvolvido reflexões acerca dos "dispositivos de visibilidade que regulam o estatuto dos corpos e o tipo de apreensão e atenção que merecem" (RANCIÈRE, 2012, p. 96). Ambos têm se dedicado a promover uma abordagem ética do aparecer (aparaître) político dos corpos, identificando que tipo de olhar e de implicações esse "aparecer" suscita junto àqueles que observam e interrogam os enquadramentos que tornam visíveis e legíveis discursos, gestos, imagens, corpos.

Segundo Butler (2011), o enquadramento, tomado como moldura que torna os vulneráveis visíveis, pode contribuir negativamente para intensificar sua precariedade e seu apagamento. Por isso, sua reflexão sobre reconhecimento e ética da justiça envolve problematizar o enquadre em busca das fissuras as quais nos indicam que a moldura não consegue determinar de forma precisa o que vemos, pensamos, reconhecemos e apreendemos.

Por vias diferentes, Rancière $(2012,2013,2019)$ se aproxima do argumento elaborado por Butler quando define o "aparecer" dos sujeitos na cena de dissenso a partir de uma intervenção, perturbação, deslocamento e reorganização de formas perceptivas dadas, a ponto de fazer com que indivíduos, palavras e objetos não possam mais ser inseridos no quadro sensível definido por uma rede de significações, nem encontrem mais seu lugar e seu tempo no sistema de coordenadas policiais onde habitualmente se localizam.

Ao observar os dispositivos de visibilidade que definem e impõem constrangimentos e cerceamentos aos modos como os corpos são 
representados na imagem, Rancière (2007, 2012, 2019) e Butler (2015) chamam nossa atenção para os mecanismos de regulação do estatuto dos corpos representados e o tipo de atenção a eles conferida. Enquadramentos articulam uma forma de biopolítica ou governo biopolítico dos corpos coletivos, cerceando comportamentos, modos de agência e possibilidades de ação. O enquadramento tem a probabilidade de promover um tipo de poder que envolve os modos de (in)visibilidade e (i) legibilidade de sujeitos e grupos, regulando o espaço e os modos de sua aparência.

O governo biopolítico dos corpos coletivos atua na produção de enquadramentos que recusam a precariedade, valorizando um conjutno limitado e dominante de formas de emanciapação e autonomia que preservam, ao mesmo tempo, o controle sobre as possibilidades de ser e existir em sociedade. Sendo assim, os enquadramentos biopolíticos configuram uma forma de governamentalidade neoliberal que estrutura o eventual campo de aparecimento e ação dos sujeitos. Segundo Judith Butler (2015, p. 14), os enquadramentos (ou quadros interpretativos) "não determinam de modo unilateral as condições do aparecer (no sentido de uma aparição performativa sobre uma cena pública) dos sujeitos e dos acontecimentos. Contudo, sua finalidade é demarcar a esfera de aparição". Assim, tornar-se visível em uma cena comunicativa de dissenso envolve não só a escolha de quadros de sentido e valores partilhados - através dos quais indivíduos serão identificados, conhecidos e nomeados - mas também a instauração de uma relação conflitiva de busca por reconhecimento, legitimidade e autonomia. Ser visível, nesse caso, articula a existência de uma imagem pública a um processo intersubjetivo e recíproco de enunciação, de fala e escuta, acolhimento e estranhamento.

Nosso intuito, nesse texto, é explorar a invenção da cena polêmica de "aparência" e de interlocução, na qual se inscreve o gesto, a palavra e o corpo do sujeito falante, e na qual esse próprio sujeito se constitui de maneira performática, poética e argumentativa a partir da conexão e desconexão entre os múltiplos nomes e modos de "apresentação de si" 
que o definem. Partimos da ideia de que, tanto para Butler quanto para Rancière, "aparecer" não é só adquirir visibilidade, mas envolve alterar o modo como sujeitos são percebidos e reconhecidos diante dos outros, o que demanda um deslocamento do olhar, uma outra forma de imaginar a alteridade e de considerar as formas de vida daqueles que se apresentam diante de nós. Nos termos das perspectivas aqui apresentadas, aparecer significa alterar os modos de disposição dos corpos, temporalidades, espacialidades e textualidades, ou seja, o gesto de reorganizar o campo em que a própria experiência é vivida.

\section{Esquemas definidores do aparecimento e da apreensão das vidas precárias}

Ao acionarmos as produções contemporâneas de Judith Butler (2004, 2015, 2016, 2017, 2018), verificamos que um dos pilares que fundamentam sua teoria sociológica, política e ética é a proposição de que a existência humana corporificada é necessariamente, ainda que não suficientemente, condicionada pela precaridade (precariouness). Esta noção é fundamenta pela autora a partir do atestado de que a condição de preservação e potencialização de qualquer existência considerada como vida é condicionada, desde a primeira infância, por relações de dependência material, simbólica e afetiva de outros seres para além de um indivíduo ou si mesmo. Ou seja, ainda que experienciemos múltiplas dimensões do existir de forma individual, a individualidade ou singularidade é precária e opaca por encontrar-se sempre suportadas por relações que excedem um self. Neste sentido, a noção de precaridade coloca em primeiro plano a relacionalidade que necessariamente condiciona nossa existência enquanto seres sociais.

A precaridade, enquanto noção que busca dar conta de uma necessária dimensão ontológica do humano, não pode ser pensada, de acordo com a autora, como essência purificada ou qualidade apartada das condições sociais e políticas que atravessam, obstruem ou fomentam a preservação e desenvolvimento de vidas humanas. Esta situação se 
revela de forma especialmente problemática quando atestamos que, sobretudo em nosso cotidiano ocidental, carências, ausências ou negações de relações e estruturas sociais de suporte existencial, muitas das vezes, não são sequer "apreendidos" como invariavelmente necessários para preservação e fomento de algumas populações, grupos ou indivíduos. Por este motivo, a distribuição assimétrica da precaridade produz, para Butler, assimétricas formas de precariedade (precarity) que nos convocam com urgência a questionar os pretensos fundamentos e condições sociais que assim as produzem, reiteram ou intensificam; questão de cunho moral, ético e político por excelência.

Ao se questionar sobre os atravessamentos sociopolíticos que modulam diferencialmente as precaridades, Butler propõe que estas são efeito de uma processual reiteração social de certos "quadros de inteligibilidade" e "normas de reconhecibilidade" que permitem ou priorizam a preservação e fomento de algumas vidas e modos de existência, enquanto legitimam ou naturalizam violência e morte de outras; estas que muitas vezes não são sequer consideradas como dignas de luto. Tais quadros esculpem seletivamente a experiência dos sujeitos, de modo que

"não podemos reconhecer facilmente a vida fora dos enquadramentos nos quais ela é apresentada, e estes enquadramentos não apenas estruturam a maneira pela qual passamos a conhecer e identificar a vida, mas constituem condições que dão suporte a essa mesma vida" (BUTLER, 2015, p. 44).

Para Butler (2004, 2011, 2015), ainda que os enquadramentos sejam condição primária para reconhecimento do outro, esses também distinguem que tipos de vidas podemos apreciar e valorizar, daquelas que não mereceriam ser consideradas. Os termos, as categorias, as convenções e regras gerais que operam em dispositivos de enquadramento modelam e transformam, por exemplo, um ser vivente em um sujeito passível de ser reconhecido através de uma forma específica de apreensão, isto é, uma forma de conhecimento associada ao sentir e ao perceber, sem utilizar conceitos. Trata-se de saber como essas normas operam para tornar certos sujeitos pessoas reconhecíveis e tornar outros decididamente 
mais difíceis de reconhecer. O problema, segundo Bulter (2015, p. 20) "não é apenas saber como incluir mais pessoas nas normas existentes, mas sim considerar como as normas existentes atribuem reconhecimento de forma diferenciada”. É possível dizer que há uma aproximação entre a perspectiva de Rancière e a abordagem de Butler quando se trata de buscar outra ordem sensível que nos permite lutar contra a hierarquização e a sujeição. Ambos tematizam o modo como um tipo de controle define e demarca o que e quem pode ser audível, visível e legível:

O esquema interpretativo tácito que distingue as vidas dignas das não dignas de consideração funciona fundamentalmente através dos sentidos, diferenciando os gritos que podemos ouvir dos que não podemos, as visões que conseguimos enxergar das que não conseguimos, (...) o que significa que deve ser travada uma luta contra as forças que procuram regular a comoção e a afetação de formas diferenciadas. (BUTLER, 2015, p. 83).

As premissas, julgamentos, desacordos, valores, predisposições afetivas, etc., que permitem aos atores sociais reconhecerem e compreenderem os fatos e percepções revelam como o enquadramento é configurado como ideia organizadora central em processos de desvelamento e construção discursiva de um problema político e dos sujeitos que a ele se articulam. Contudo, o enquadramento não é capaz de conter completamente o que transmite e, por isso, se rompe toda vez que tenta dar uma organização definitiva a seu conteúdo (BUTLER, 2015). Nesse processo de ruptura contínua, os termos pelos quais os sujeitos são nomeados e conhecidos são produzidos, deslocados, questionados e alterados. Trata-se, de acordo com Butler, de saber como funcionam as operações de aparecimento que tornam certos sujeitos e grupos reconhecíveis e valorizáveis, enquanto outros são claramente destituídos de respeito e consideração.

É importante salientar que, ainda que precaridades e vulnerabilidades sejam diferencial e assimetricamente distribuídas num dado contexto social, marcando assim vidas como dignas ou não de existência preservação e potencialização, a reflexão da autora pretende superar a 
oposição histórica com a qual estas noções foram associadas com outras, tais como agência, criatividade, insurgência e resistência política. Segundo ela, quando sujeitos vulneráveis e precarizados são apreendidos a partir da produção de um espaço de aparecimento delineado por sua ação política, desvelam a potência resistente de colocar em questão uma normatividade social injusta (VELOSO; MARQUES, 2018; VELOSO; 2020).

Assim, as reiterações práticas dos "esquemas de inteligibilidade" que compõem os enquadramentos e das "normas de reconhecibilidade" a eles atreladas, não determinam o destino de uma corporeidade, identidade ou de um sujeito num dado contexto social, ainda que condicione papéis, funções, ações sociais e modos de existência. Butler encontra a potência de resistência na reiteração performativa, nas ressignificações e deslocamentos que fraturam ordens sociais hegemônicas:

O performativo não é um ato singular utilizado por um sujeito já estabelecido, mas uma das formas potentes e insidiosas na qual o sujeito é chamado a se tornar um ser social a partir de lugares difusos e é inserido no social por meio de um conjunto de interpelações poderosas e diversas. Nesse sentido, o performativo social é uma parte crucial não só de afirmação do sujeito, mas também do consequente questionamento político e da reformulação do próprio sujeito. O performativo não é somente uma prática ritual: é um dos rituais mais influentes na formação e reformulação dos sujeitos. (BUTLER, 2005, p. 256).

Nesse sentido, "performatividades" produzidas por corporeidades atravessadas por vulnerabilidades, violência e danos, tal como realizado, por exemplo, por indivíduos, grupos e movimentos sociais em suas interações cotidianas ou em protestos, possibilitam a emergência de um ato de contestação à injustiças que pretensamente são atualizadas e naturalizadas num dado contexto. "Essas formas coletivas de resistência são estruturadas de maneira muito diferente da idéia de um sujeito político que estabelece sua agência ao subjugar sua vulnerabilidade - esse é o ideal masculinista ao qual devemos continuar nos opondo" (BUTLER, 2016, p. 24). 
A autora confere especial ênfase à necessidade de se compreender "performatividades" políticas não apenas a partir dos efeitos interacionais de múltiplas escalas que produzem, mas também a partir das redes e relações de aliança ou oposição, humanas, não-humanas e/ou extra-humanas, que possibilitam ou criam obstáculos para que corporeidades disputem o campo perceptivo social ou "espaço de aparecimento" (BUTLER, 2018). Cabe ressaltar que este "espaço de aparecimento", apesar de remeter ao argumento de Hannah Arendt sobre a praça pública, não é considerado pela autora como uma esfera pública apartada ou tomada como dada para um posterior emergir da política, principalmente quando consideramos que qualidades públicas ou privadas de espaços, tempos e materialidades são já atravessados por disputas e/ou negociações entre distintos grupos sociais menos ou mais vulneráveis em relação uns aos outros.

O "aparecimento" pode designar uma presença visível, palavras faladas, mas também representação em rede e silêncio. Além disso, temos que ser capazes de pensar em tais atos como ação plural, pressupondo uma pluralidade de corpos que apresentam o seu propósito convergente de modos que não requerem uma conformidade estrita com um tipo singular de ação, ou um tipo singular de reivindicação, e que não constituem juntos um tipo singular de sujeito. (BUTLER, 2018, p. 157).

O espaço de aparecimento envolve a compreensão de como sujeitos vulneráveis enunciam suas demandas e, ao mesmo tempo suas vulnerabilidades, expondo corpos que precisam de apoio, mas não no sentido de "eliminarem" o que a ordem hierárquica aponta negativamente como "precariedade". O aparecimento político em espaços pretensamente ou potencialmente públicos expressa, assim, uma "contradição performativa" que não apenas coloca as próprias normas sociais em xeque, mas também a própria significação socialmente compartilhada de suas próprias vulnerabilidades:

Há uma resistência corporal plural e performativa no trabalho que mostra como os corpos estão sendo manipulados pelas políticas sociais e econômicas que estão dizimando os meios de subsistência. Mas esses 
corpos, ao mostrarem essa precariedade, também estão resistindo a esses mesmos poderes; eles encenam uma forma de resistência que pressupõe uma vulnerabilidade de tipo específico e se opõe à precariedade. (BUTLER, 2016, p. 20, nossa tradução).

Os espaços ou cenas de aparecimento são efeitos de alianças e agenciamentos que são orientados pelo cuidado e responsabilidade com o outro mais vulnerável. Para Butler, sujeitos e corporeidades podem, ainda que em breves e infinitesimais instantes, introduzir fissuras no tempo-espaço social que os engloba, a partir de tensões, deslocamentos e/ou mesmo reconfigurações de rotulações, valores, estimas sociais e mesmo estética do olhar "normatizado" e "normatizante" que, em outros contextos, são reiterados pela norma.

O “espaço de aparecimento" de Butler leva em conta a exposição dos corpos individuais e coletivos, revelando sua constituição relacional e dependente de alianças que podem ser estabelecidas "entre as pessoas que vivem juntas com esse propósito, não importa onde elas estejam, o que significa que assim como qualquer ação acontece em um lugar localizado, ela também estabelece um espaço que pertence à aliança propriamente dita” (BUTLER, 2018, p. 73).

Ao mobilizar a noção de "espaço de aparecimento" proposta por Hannah Arendt (2009), Butler pode afirmar que o "aparecimento” na cena (pretensamente) pública é condição necessária para a política democrática e a emergência de existências que afirmam que são vivas e dignas de viver, contestando sua pretensa invisibilidade e indignidade de luto. Não obstante, cabe ressaltar que espaços ou "cenas de aparecimento" dependem de um afetar e ser afetado, de uma mediação do aparecer que promova uma exposição e despossessão de si mesmo perante o outro, seja por um gesto, performance cênica ou protesto coletivo:

[...] aparecemos para alguém e que o nosso aparecimento tem que ser registrado pelos sentidos, não apenas os nossos, mas os de alguém mais. Se aparecemos, devemos ser vistos, o que significa que nosso corpo deve ser enxergado, e seu som vocalizado deve ser ouvido: o corpo deve entrar no campo visual e audível...o aparecimento não é um momento 
necessariamente morfológico quando o corpo se arrisca a aparecer não apenas para falar e para agir, mas também para sofrer e comover, para engajar outros corpos, para negociar um ambiente do qual se depende, para estabelecer uma organização social com o objetivo de satisfazer as necessidades. (BUTLER, 2018, p. 175).

Se Judith Butler vai além de Hannah Arendt (2009) ao afirmar que uma "esfera pública" não é um espaço que simplesmente se adentra, como uma "ágora" que aguarda que um povo ou cidadão fale ou se expresse pela justificação recíproca para que seja visto e ouvido, é preciso pensar ainda sobre os suportes materiais, simbólicos e afetivos para que os sujeitos tenham condições de "aparecer" em outros contextos para além daqueles que tendem a reiterar seu esquecimento, alienação e exclusão.

Assim, não há como promover a aparição sem questionar as formas de poder assimétricas que delimitam a esfera do visível. Isso não significa desconsiderar as lógicas de gestão, de governamentalidade e de controle que partem das instituições e suas racionalidades estratégicas. Contudo, implica reconhecer que há momentos nos quais as normas podem ser rompidas, adaptadas ou substituídas por outras. Nos termos de Rancière, a subversão desestabiliza e interpela a ordem da polícia qualificando-a, deixando-a menos policialesca, ainda que ela continue a ser gestão (PRADO, 2019).

Ressaltamos que Butler e Rancière estão interessados nas rupturas que podem ser feitas no sistema de visibilidade, ou seja, em como é possível subverter a ordem dominante e buscar momentos nos quais outras possibilidades de aparecimento dos sujeitos podem emergir, ainda que temporárias. Eles caracterizam a subversão como um processo estético e performativo a partir da apropriação e torção de modos de dizer, fazer e ser. Enquanto Butler enfatiza a apropriação de novos modos de ser através da repetição inexata das normas, Rancière enfatiza a apropriação de tempos e espaços por meio da desidentificação e da subjetivação. E ambos destacam que política não pode se transformar em gestão: ela precisa ser reinventada, sem a utilização inquestionada da gramática 
moral que classifica os sujeitos e seus corpos e permitir que os conflitos encontrem lugares de expressão no mundo público.

Nos termos de Butler, o ato político precisa revelar como certo modo de vida se produziu como uma verdade possível a partir de sua ação dentro da norma, mas de uma ação que a reitera e recria ao mesmo tempo. Já nos termos de Rancière, o ato político precisa revelar os mecanismos de constituição de certa verdade, que evidenciam a contingência de qualquer ordem hierárquica. Para ele, o sujeito se posiciona sempre entre identidades, entre formas de regulação policiais e a políticas, em busca de uma reconfiguração do campo de sua experiência e de sua condição de enunciação, "especialmente em determinados contextos onde os chamados ruídos dissonantes estão às margens dessas formas de governança que atuam a partir da fabricação de lugares identitários" (PRADO, 2019, p. 209).

A desidentificação é um processo que junta e separa as identidades, demonstrando como elas estão já revestidas, já nomeadas no seio das hierarquias pelas tecnologias sociais de gestão dos tempos e espaços. Assim, é um processo que permite que os sujeitos escapem dos discursos avaliativos e biolegitimadores que prescrevem e determinam suas existências e expectativas de mudança. Resistir à fixação identitária é distanciar-se de uma condição de reconhecimento preparada. Para Rancière, como veremos a seguir, a desidentificação é um processo de subjetivação no qual são questionados e redispostos os códigos, tempos e espaços que

definiam e tornavam um indivíduo ou grupo inteligíveis até então. É a afirmação de uma racionalidade alternativa que pode assegurar reexistências e sobrevivências.

\section{A cena de dissenso e a insurgência política do "apparaître"}

O conceito de "aparência” em Rancière (2018b, 2019) não se restringe a algo superficial ou ao modo como alguém ou algo se manifesta publicamente. Aparecer (apparaître) é um gesto estético e político que 
promove uma outra forma de estruturação do "pensável”, envolvendo a alteração de um regime de percepção, de leitura e de escuta por meio do qual elementos diversos se justapõem e se atritam de modo a permitir um deslocamento de nossa posição em relação ao modo como apreendemos, percebemos e respondemos às demandas do outro e aos eventos do mundo.

O aparecer é uma experiência estética de ruptura com uma ordem prefigurada que programa nossa percepção e nossa razão para atendermos de modo consensual a esses apelos. Assim, o "aparecer" é uma prática que reconfigura a visibilidade e a inteligibilidade que medeiam nossas interações com a alteridade. Esse gesto é insurgente, porque desafia a hierarquia que atrela o olhar e a escuta a dispositivos de controle e previsibilidade.

De modo mais amplo, seria possível afirmar que Rancière está interessado em como pensar acerca de um reposicionamento dos corpos, em como produzir deslocamentos e fissuras nos modos naturalizados de apreensão e explicação dos eventos, em como inventar "uma forma de interromper a máquina da explicação das coisas" (RANCIÈRE, 2018b, p. 17). Segundo Rancière, o tipo de operação que pode mudar a "distribuição do visível e do pensável” (RANCIÈRE, 2019, p. 50) é a montagem da cena.

A cena pode ser definida como a criação de uma possibilidade de enunciação dos sujeitos que vai além dos lugares e tempos fixados pela ordem consensual hierárquica (ordem policial ${ }^{5}$ ). Dito de outro modo, em uma cena de dissenso é possível perceber como, na reiteração de normas e códigos de controle e conduta, há potencialidade de acompanhar os traços históricos e as tentativas de produzir momentos de deslocamento do regime sensível que define as legibilidades e inteligibilidades destinadas desigualmente aos sujeitos que questionam uma

5 "Eu defini a polícia como uma forma de partilha da sensível, caracterizada pela adequação imaginária dos lugares, das funções e das maneiras de ser, pela ausência de vazios e suplementos. (...) Polícia, para mim, não define uma instituição de poder, mas um princípio de partilha do sensível no interior da qual podem ser definidas as estratégias e as técnicas do poder." (RANCIËRE, 2010, p.78). 
identidade social a eles imposta. Ir além das identidades sociais e scripts previamente definidos delineia um conflito que pode promover oportunidades de "inventar a cena na qual palavras ditas se tornam audíveis, objetos se tornam visíveis e indivíduos podem ser reconhecidos" (RANCIÈRE, 2010, p. 124).

Penso que a questão da cena é também ligada muito fortemente à questão da aparência, ao fato de que a aparência não é o contrário da realidade, mas a cena da manifestação. A teatralidade é a construção de um outro universo de aparências: o fato de fazer aparecer o que não aparecia, ou de fazer aparecer de forma diferente o que aparecia sob um certo modo de visibilidade e inteligibilidade. A teatralidade está fortemente ligada a isso, saber que tudo se joga na apresentação daquilo que aparece (teatralidade própria da insurreição) (2018b, p. 17).

A cena promove, assim, outras possibilidades de arranjos e articulações entre temporalidades e espacialidades de modo a alterar a dinâmica do aparecer dos sujeitos e dos acontecimentos, reorganizando o campo do visível e retirando-o de uma ordem representativa consensual. De acordo com Rancière (2019, p. 48), o que é importante na ideia de cena é o fato de que ela constrói uma visibilidade e um "aparecer" a partir de tentativas de enquadrar, montar e distribuir as experiências e seus registros questionando a forma histórica e social assumida por esses arranjos, tensionados entre o corte e a construção ou tecelagem de um "comum”. A situação presentificada pela cena produz um tipo de corte ou descontinuação que demonstra a arbitrariedade ou a violência da partilha vigente do sensível e a possibilidade da diferença. Contudo, esse corte não é resultado de uma interrupção instantânea, desvinculada de processos sociohistóricos de luta e conflito: "não estamos lidando com a descontinuidade radical que faz com que o que era impossível ontem seja possível amanhã" (RANCIÈRE, 2018b, p. 31). A cena coloca em evidência uma singularidade e conecta a interrupção da ordem policial a processos mais amplos que geralmente são tornados ilegíveis através de mecanismos de separação entre o cotidiano dos sujeitos e o inalcançavel de uma totalidade impenetrável representada pela governamentalidade 
neoliberal. Mas é importante lembrar que a cena de dissenso não está necessariamente relacionada a esse modo específico de partilha policial do sensível: assim como existem diferentes regimes policiais, diferentes tipos de cena são montados para evidenciar arranjos hierárquicos específicos.

A noção de cena comporta duas ideias: aquela de um corte e aquela de uma certa arquitetura do que é dado. (...) A questão é: o que é dado a perceber? Que lugar possuem os indivíduos que são dados a ver nessa arquitetura? (RANCIÈRE, 2019, p. 49).

Como veremos mais adiante, é essa ideia da "arquitetura do que é dado" que permite uma aproximação entre as perspectivas de Rancière e de Butler: a cena promove alterações nos enquadramentos que estruturam a arquitetura do visível. Essas alterações são fruto, ao mesmo tempo, da emergência de processos de subjetivação política e do trabalho de reflexão daqueles que se dedicam à operação de montagem da cena a partir da aproximação de documentos, imagens, palavras, registros históricos que trazem à tona o movimento político e histórico de insurgência. A cena vivida, produzida, desdobrada pela operação de subjetivação existe como singularidade que pode ou não ser ressignificada no trabalho de montagem.

Certos sujeitos que não são considerados criam uma cena polêmica comum onde colocam em discussão o status objetivo do que é dado e impõem um exame e discussão dessas coisas que não eram visíveis ou consideradas anteriormente. (RANCIÈRE, 2010, p. 125).

Ao explicar como a cena compõem o método da igualade, Rancière (2018b) ressalta que sua função epistemológica consiste em recusar uma lógica causal de explicação que privilegia a busca de algo que se esconde atrás das aparências. A cena permite explorar o que está em jogo na singularidade escolhida para ser contemplada, ela associa a montagem de eventos que se localizam em uma temporalidade descontínua, a partir da escolha de um certo modo de racionalidade: "penso que na espessura de um acontecimento singular podemos ler o conjunto dos 
vínculos que definem uma singularidade política, artística ou teórica" (RANCIÈRE, 2018b, p. 22).

O trabalho de construção da cena é partilhado entre experiências de subjetivação política e pensamentos que evidenciam a agência política de atores sociais e intelectuais que desejam evidenciar uma "poética do conhecimento", alterando as coordenadas no campo em que as experiências se dão. Tal poética compreende o método da cena enquanto conjunção, enquanto gesto ético e estético de colocar juntos os corpos, gestos, olhares, palavras e significações de modo a produzir uma "ficção" que revele um modo de racionalidade que não pode ser explicado por aquilo que está "fora de cena", mas pela disposição e montagem dos elementos que a compõem.

Ficção no sentido de que a cena que eu construo, eu a invento. Mesmo se parto de um texto, eu o reinvento como texto de um personagem que observa uma obra ou assiste a um espetáculo. Eu a invento com elementos verificáveis, mas há sempre um momento de mise en scène. No geral, é a mesma coisa que fiz na Noite dos Proletários, onde há, ao mesmo tempo, uma massa enorme de arquivos e de cenas que são, na verdade, conjecturais. Eu as ofereço como foram contadas, ou eu as conto novamente sob a forma de uma probabilidade. Há sempre um jogo a partir das possibilidades que o acontecimento oferece, enquanto dado, de constituir uma cena, uma forma de enunciação, um espaço do espectador. (RANCIÈRE, 2018b, p. 125).

Assim, enfatizamos o quanto a noção de cena está vinculada ao trabalho criativo, fabulador e resistente da narrativa ficcional, pois ela promove uma multiplicidade de mundos e formas de experimentação que não são as nossas e, por isso mesmo, nos permitem pensar, dizer o mundo e a refletir sobre ele de uma outra maneira. A ficção permite "outras maneiras de identificar os acontecimentos e os atores e outras formas de articulá-los para construir mundos comuns e histórias comuns. (RANCIÈRE, 2017, p. 13).

A montagem permite a aproximação de temporalidades, espacialidades, corporeidades e linguagens heterogêneas, cujo tensionamento e 
choque pode fazer vacilar as incoerências das representações e o modo como elas usualmente trazem, ao mesmo tempo, os conflitos e suas soluções pacíficas.

A cena é mais o que expõe as diferentes maneiras como uma mesma coisa pode ser percebida: ela é sempre, para mim, o momento no qual as coisas podem vacilar, ser sacudidas ou revertidas. (...) Há subjetivação, para mim, quando há uma reconfiguração das coordenadas de um campo da experiência. Isso é o que está em jogo na cena. (2018b, p. 31)

A racionalidade da ficção deriva das diferenças e rupturas que produz no seio de um continuum supostamente homogêneo ensejado pela ordem causal e hierárquica de organizar e habitar o tempo (CALDERÓN, 2020). A cena permite, portanto, a ordenação ficcional de uma singularidade a partir da qual se pode revelar "o que estava indexado sob o registro do único real possível, apresentando a esse real ordinário e já consensual uma desierarquização e uma possibilidade outra de aparecer" (RANCIÈRE, 2019, p. 55). A cena e sua montagem produzem momentos de rêverie (devaneio fabulador):

Momentos que explodem, dinamitam o tempo contínuo, o tempo dos vencedores: permitindo a abertura de um outro tempo, um tempo comum, nascido nas brechas operadas no primeiro: não um tempo do sonho que faria cair no esquecimento o tempo sofrido ou projetaria um paraíso em devir, mas um tempo que se apresenta outramente, confere um peso diferente a tal instante, o conecta a um tal outro articulando outros instantes (RANCIÈRE, 2018c, p. 36).

Assim como Butler, vemos que Rancière se preocupa com a maneira como corpos e enunciações antagônicas aparecem sobre a cena, pois a definem "enquanto conjunção, enquanto a operação de colocar juntos os corpos, olhares, palavras, gestos e significações” (2018a, p.29). O aparecer possui uma dimensão emancipatória, porque envolve uma outra maneira de pensar e realizar uma distribuição e organização dos corpos e das capacidades, modificando um campo de experiência e construindo um mundo comum alternativo em relação àquele no qual as posições 
identitárias, expectativas e temporalidades já estavam assinaladas e distribuídas. Alterar as condições de aparecimento é também fraturar o dispositivo que controla quais corpos e quais aparências são dignas de serem consideradas como legítimas em detrimento das aparências percebidas como abjetas e desprezíveis.

\section{Considerações finais}

A nosso ver, uma primeira aproximação possível entre as abordagens de Butler e Rancière acerca das condições do aparecimento político dos sujeitos sobre uma cena de conflito se relaciona ao modo como definem tais condições, apontando profundas assimetrias nas formas de sua apreensão e inteligibilidade, dificultando processos de reconhecimento e de minimização das injustiças. Ambos apostam na importância da alteração dos esquemas de legibilidade e inteligibilidade do mundo para que possamos imaginar e efetivamente construir uma ordem comum não hierárquica, que reconheça a dignidade das existências.

Derivada dessa primeira aproximação, uma segunda interface entre a reflexão de Butler (2016, 2017, 2018) e Rancière se encontra na potência política dos "espaços de aparecimento" dos corpos, de suas experiências e formas de vida, levando em especial consideração as redes de suporte, agenciamentos, alianças e performatividades que constituem e introduzem diferença em suas interações e lutas sociais.

Acreditamos que Butler e Rancière apostam no aparecimento como operação de resistência que altera legibilidades e inteligibilidades. O gesto subversivo em Butler confere destaque à presença de uma corporeidade que inventa uma resposta diferente daquela esperada ou prevista. Em Rancière, a modificação das coordenadas da experiência que inscrevem os corpos no tempo e no espaço se inicia quando um corpo vulnerável consegue acessar o "desmedido momento" (RANCIÈRE, 2017, p. 155), ou seja, "o momento de sacudida que se conserva entre o nada e o tudo, que fica nessa fronteira na qual as vidas que vão cair no nada se elevam" e são retiradas do inframundo do tempo da reprodução e da hierarquia. A nosso ver, o gesto político narrado por Butler 
na construção de alianças abre um hiato temporal e espacial desviante, revelando sujeitos vulneráveis que criam, muitas vezes em meio a um sofrimento atroz, "uma outra maneira de habitar o tempo, uma outra maneira de sustentar um corpo e um espírito em movimento." (RANCIÈRE, 2018c, p. 34).

Butler e Rancière definem a aparição pública dos sujeitos como um choque que arranca os corpos e suas potencialidades de enquadramentos estigmatizantes e de modos causais e deterministas de ordenação narrativa da história. Ambos questionam as regras sensíveis de apreensão e inteligibilidade dos corpos, construindo do que estava programando para poder ser visto. O aparecer comporta, para ambos, a quebra de expectativas, a expansão da experiência enunciativa, "alterando o estatuto do visível, da maneira como olhamos as coisas e de como nos movemos entre elas" (RANCIÈRE, 2019, p. 51).

A combinação entre a apropriação da norma em Butler e a desidentificação em Rancière nos mostra como as subversões podem derivar da apropriação dos tempos e espaços que antes não eram legitimamente designados aos sujeitos dentro da ordem policial ou dos esquemas de controle biopolítico: nessas apropriações os sujeitos se desidentificam e/ ou permitem a desidentificação com uma posição que lhes foi previamente definida na hierarquia vigente, modificando as relações traçadas entre elementos que os situam na ordem social.

Tais "relações novas" derivam, segundo Rancière (2019), da reconstituição da rede conceitual que torna um enunciado pensável e que modifica as condições de seu aparecimento. O aparecimento (e o espaço cênico que ele aciona) consiste, assim, em produzir um arranjo, um reenquadre, uma reorganização de formas perceptivas dadas, uma recomposição da ordem que sustenta uma dada narrativa, uma montagem que evidencie um intervalo, um espaço que torna possível habitar o "entre". As sobrevivências ligadas ao espaço de aparecimento se produzem nas contínuas fraturas e remodelagens das visibilidades e inteligibilidades, na construção de alianças entre os corpos e imaginários, que se relacionam à potência política que vidas precárias possuem de produzir 
uma "contradição performativa" dirigida aos agentes da governamentalidade e da sujeição (VELOSO, 2020, p.157).

A cena de aparecimento se configura pelo excesso, pelo suplemento, por aquilo que desborda os lugares e tempos fixados pela ordem policial e pelos enquadramentos biopolíticos e necropolíticos. Por este motivo, não apenas em protestos ou agenciamentos de larga escala, a cena é explicitamente compreendida como uma forma de experimentar o tempo potencialmente em quaisquer escalas e territorialidades, nos macro e microacontecimentos (MARQUES \& PRADO, 2018, p.29); é o excesso que vai caracterizar a "cena de dissenso", assim como também a emergência dos "sem-parte" e o processo de "desidentificação" (RANCIÈRE, 2012).

Ao colocar em primeiro plano as vulnerabilidades corporificadas que constituem uma ação social, a cena de aparecimento em Butler considera como o acesso e restrição à redes de suporte material e simbólico introduzem diferença na própria formação e "performatividade" de uma ação política e em que sentidos estes elementos dinâmicos são atualizados, contestados e/ou reapropriados (WOODFORD, 2017). Nesse sentido, mapear como sujeitos políticos experienciam suas vulnerabilidades, violências e danos pode nos levar a compreender as próprias redes de aliança e oposição que estes formam e os efeitos que as mesmas produzem na própria política performada, por exemplo, num protesto coletivo.

Sob esse aspecto, mapear performatividades e desidentificações é também um movimento de mapeamento das próprias estruturas sociais de "inteligibilidade" e "reconhecibilidade" que são atualizadas, denunciadas ou enunciadas como mais justas num dado contexto. A exposição corporificada de si, sempre atravessada por vulnerabilidades, tem tanto a possibilidade de reiterar esquemas normativos dominantes, produzindo efeitos imprevisíveis e perversos, quanto de expor falhas, violências e injustiças socialmente naturalizadas (VELOSO, 2017; VELOSO;MARQUES, 2018; VELOSO, 2020). 
Sob esse viés, Rancière e Bulter nos convocam a estudar processos políticos em seu "vir-a-ser", ou seja, desnaturalizando termos como agência, sujeito e política como noções apriorísticas que universalmente categorizam ou explicam racionalidades, corporeidades, agenciamentos, práticas e territórios que se relacionam agonisticamente numa luta por justiça. Ambos revelam como sobrevivências se relacionam aos esforços feitos em momentos de insurgências coletivas, de povos em aliança, para reconstruir uma forma de vida comum. Assim, ao mesmo tempo em que a cena de aparecimento está instalada em um espaço-tempo de ruptura, há

[...] um esforço para instalar uma duração desses momentos de reconstrução de uma forma de vida comum nas experiências de produção, de troca, de circulação da informação, de transmissão de saberes e de oferta de cuidados que tecem as redes de uma solidariedade nos conflitos do presente, que é também a antecipação de uma forma de vida ainda por vir, uma forma de vida comum livre da hierarquia dos tempos e das capacidades (RANCIÈRE, 2018c, p. 46-47).

Nos chama a atenção o fato de Rancière destacar as articulações e vínculos de pertencimento que dão origem a experiências ricas em múltiplas linhas de fuga que permitem aos sujeitos se constituírem e aparecerem como agentes de suas vidas. Assim como Butler, ele aponta como os afetos e vínculos tecidos em meio aos conflitos evidenciam tudo o que os sujeitos da política fazem para manter sua dignidade, sua integridade, como reparam continuamente o mundo ordinário, para que possam construir condições de autopreservação fazendo parte de um "comum livre da hierarquia de tempos e capacidades".

Essa é uma questão importante, uma vez que o modo como os sujeitos tecem juntos uma rede de manutenção da vida, vai articular a trama da solidariedade, dos pertencimentos, do traço de humanidade que teima em ser desrespeitado. As articulações produzidas pelas insurgências permitem à vida manter sua trama, sua forma, ao mesmo tempo que auxilia os sujeitos a encontrar um ritmo, um estilo viável que resiste à dor, ao sofrimento, ao ataque. É como se fossem barricadas feitas de 
vulnerabilidades e resistências que, amalgamadas pelos afetos, atuam juntas para realizar uma reparação e uma fabulação contínua da vida que ameaça romper-se a cada instante.

\section{Referências}

ARENDT, H. A vida do espírito: o pensar, o querer, o julgar. Rio de Janeiro: Civilização Brasileira, 2009.

BUTLER, J.Precarious Life. London, Verso, 2004.

BUTLER, J. Lenguaje, poder e identidade. Síntesis, Madrid, 2005.

BUTLER, J. Vida precária. Contemporânea - Revista de Sociologia da UFSCar, São Carlos, v.3, n.1, p. 13-33, 2011.

BUTLER, J. Quadros de guerra: quando a vida é passível de luto?. Rio de Janeiro: Civilização Brasileira, 2015.

BUTLER, J. Rethinking Vulnerability and Resistance. In: BUTLER, J.; GAMBETTI, Z.; SABSAY, L. (Ed.).Vulnerability in resistance. Duke University Press, 2016.

BUTLER, J. When gesture becomes event. In: Inter Views in Performance Philosophy. Palgrave Macmillan, London, 2017. p. 171-191.

BUTLER, J. Corpos em Aliança e a política das ruas. Rio de Janeiro: Civilização Brasileira, 2018.

CALDERÓN, A. S. Reivindicación de las apariencias en el trabajo de Jacques Rancière. Daimon. Revista Internacional de Filosofía, n. 79, p. 21-35, 2020.

MARQUES, Â.; PRADO, M. A. M. O método da igualdade em Jacques Rancière: entre a política da experiência e a poética do conhecimento. Revista Mídia e Cotidiano, v. 12, n. 3, p. 7-32, 2018.

PANAGIA, Davide. Dissenting words: a conversation with Jacques Rancière. Diacritics, v. 30, n.2, p.113-126, 2000.

PRADO, M. A. M.. Emancipações, subjetivações políticas e a questão democrática. In: COSTA-VAL, A.; GUERRA, A. M.; PRADO, M. A. M.; ROCHA, G. M. Confins do Político. Curitiba: CRV, 2019, p. 205-228.

RANCIÈRE, J. O desentendimento: política e filosofia. Tradução Ângela Leite Lopes. São Paulo: Ed. 34, 1996.

RANCIÈRE, J. The method of equality: an answer to some questions. In: ROCKHILL, G.; WATTS, P. (eds.). Jacques Rancière: History, Politics, Aesthetics. Duke University Press, 2009. p. 273-288.

RANCIÈRE, J. O espectador emancipado. São Paulo: Martins Fontes, 2010.

RANCIÈRE, J.O destino das imagens. Rio de Janeiro: Contraponto, 2012.

RANCIÈRE, J. Aisthesis: scenes from the aesthetic regime of art. London: Verso, 2013.

RANCIÈRE, J. Les bords de la fiction. Paris : Éditions du Seuil, 2017.

RANCIÈRE, J. O desmedido momento. Serrote, n. 28, 2018a, p. 77-97.

RANCIÈRE, J. La Méthode de la scène. Paris: Éditions Lignes, 2018b. 
416 ENQUADRAMENTOS, CENAS DisSENSUAIS E O APARECER ANTIERÁRQUiCO

RANCIÈRE, J. Le temps modernes. Paris: La Fabrique, 2018c.

RANCIÈRE, J. Le travail des images. Conversations avec Andrea Soto Calderón. Dijon : Les Presses du Réel, 2019.

RANCIÈRE, J. The politics of aesthetics: the distribution of the sensible. London: Continuum, 2004.

VELOSO, L. H. N. Linhas de fuga, agenciamentos e corporeidades: reflexões sobre dimensões infinitesimais da luta antimanicomial de Belo Horizonte. Idealogando: revista de ciências sociais da UFPE, n.1, v. 2, p. 34-54, 2017.

VELOSO, L., MARQUES, A. C. S. Vulneráveis ou vítimas? A experiência das redes de luta antimanicomial em Belo Horizonte e a construção relacional de biopotências. Lumina, v. 12, n. 2, p. 59-78, 2018.

VELOSO, L. "Remédio anti-covardia": cartografia de vulnerabilidades, comunicação e política na construção e performatividade do dia de luta antimanicomial. 2020. $201 \mathrm{f}$. Dissertação (Mestrado em Comunicação Social) - Faculdade de Filosofia e Ciências Humanas, Universidade Federal de Minas Gerais, Belo Horizonte, 2020.

WOODFORD, C. Subjects of Subversion: Rancière and Butler on the Aesthetics of Politics. In: Street A., Alliot J., Pauker M. (eds) Inter Views in Performance Philosophy. Performance Philosophy. Palgrave Macmillan, London, 2017, p. 205-218.

\section{Sobre os autores}

Ângela Cristina Salgueiro Marques - Doutora em Comunicação Social pela UFMG, professora do Departamento de Comunicação Social dessa instituição, atuando na graduação e pós-graduação.

Lucas Henrique Nigri Veloso - Mestre em Comunicação Social pelo PPGCOM/UFMG. Doutorando em Ciência Política pelo PPGCP/UFMG.

Marco Aurélio Máximo Prado - Pós-Doutorado na Universidade de Massachusetts/Amherst. Doutor em Psicologia Social pela Pontifícia Universidade Católica de São Paulo. Professor do Programa de Pós-Graduação em Psicologia PPGPSI/UFMG.

No presente artigo, todos os autores participaram ativamente da discussão dos resultados; e realizaram a revisão e aprovação da versão final do trabalho.

Data de submissão: 11/08/2020

Data de aceite: $03 / 11 / 2020$ 